\title{
IDENTIFIKASI KARAKTERISTIK ABU TERBANG JENIS ALUMINO-SILIKAT
}

\author{
Ernesto Silitonga \\ Dosen Pengajar Jurusan Pendidikan Teknik Bangunan, Fakultas Teknik, UNIMED, Medan \\ Surel : ernestosilitonga@unimed.ac.id \\ Diterima : 26 November 2017; Disetujui : 30 November 2017
}

\begin{abstract}
ABSTRAK
Circulating Fluidized Bed (CFB) merupakan teknik dimana pekerjaan mengutamakan material yang dihasilkan memiliki emisi polutan yang lebih rendah dibanding metode klasik. Tujuan utama dari penelitian ini adalah mengidentifikasi dua jenis abu terbang Alumino-Silikat yang berbeda yang berasal dari pembakaran Circulating Fluidized Bed (CFB). Dalam upaya mengidentifikasi karakteristik kedua abu terbang ini, langkah pertama yaitu melalui karakteristik origin dari abu terbang tersebut, contohnya berdasarkan distribusi diameter partikel, karakteristik mineralogi. Langkah berikutnya dalam mengidentifikasi karakteristik abu terbang direalisasikan dengan bantuan Percobaan Chapelle yang bertujuan untuk menentukan persentase $\mathrm{CaO}_{\text {free }}$ yang tersedia untuk reaksi pozzolanic dari abu terbang. Percobaan memperlihatkan bahwa abu terbang AT/AS-1 memiliki aktivitas yang lebih intens dibanding AT/AS-2. Berdasarkan hasil percobaan dapat disimpulkan dapat kita katakan bahwa rumusan ideal untuk Sodeline adalah campuran yang mengandung $75 \%$ Sodeline, 15\% kapur dan 10\% semen. Memang, campuran ini lebih kuat dan lebih tahan terhadap serangan sulfat
\end{abstract}

Kata Kunci : abu terbang, distribusi diameter partikel, karakter mineralogy. Percobaan Chapelle

\begin{abstract}
Circulating Fluidized Bed (CFB) is a technique where the job of prioritizing the resulting material has lower pollutant emissions than the classical method. The main purpose of this study was to identify two different types of fly ash Alumino-Silicate derived from CFB. In order to identify the characteristics of these two fly ashes, the first step is through the origin characteristics of the fly ash, for example based on the particle diameter distribution, mineralogical characteristics. The next step in identifying the characteristics of fly ash is realized with the help of the Chapelle Test. This test is aimed to determine the percentage of $\mathrm{CaO}_{\text {free }}$ which will be available for the pozzolanic reaction of fly ash. Experiments show that AT / AS-1 ash fly has more intense activity than AT / AS-2. Based on the results of the experiment it can be concluded that we can say that the ideal formula for Sodeline is a mixture containing $75 \%$ Sodeline, $15 \%$ lime and $10 \%$ cement. Indeed, this mixture is stronger and more resistant to sulfate attacks.
\end{abstract}

Keywords: fly ash, particle diameter distribution, mineralogy character. Chapelle's experiment

\section{Pendahuluan}

Upaya dalam mengurangi dampak negative pada lingkungan telah lama direalisasikan pada pertambngan batubara. Metode Circulating Fluidized Bed (CFB) merupakan salah satu usaha dalam mengurangi emisi polutan yang lebih rendah. Penggunaan semen dan kapur dalam proses stabilisasi telah dikenal dapat meningkatkan performa geoteknik. Beberapa penelitian yang telah dilakukan sebelumnya, Abu terbang telah dikenal dapat meningkatkan performa beton ataupun stablisasi tanah. Pada penelitiannya, Silitonga merealisasikan pekerjaan stabilisasi limbah pelabuhan hasil pekerjaan pengerukan dari pelabuhan Port en Bessin dengan menggunakan kapur dan semen sebagai campuran, hasil penelitian memperlihatkan bahwa sedimen terkontaminasi setelah distabilisasi dengan kapur dan semen memperlihatkan peningkatan performa untuk digunakan sebagai material pengganti dalam pekerjaan pembangunan jalan [1][2][3]. Seperti yang telah diketahui bahwa tanah bermasalah terutama dengan tingkat polusi tinggi sangat susah untuk distabilisasi 62 


\section{Ernesto Silitonga}

menghambat reaksi hidratasi semen atau kapur. Penelitian yang dilakukan oleh Silitonga, Hasil percobaan daya tekan pada stabilisasi sedimen hasil pekerjaan pengerukan terkontaminasi logam berat memperlihatkan peningkatan yang cukup signifikan apabila ditambah Silica Fume [4][5][6][7]. Makalah ini berkonsentrasi untuk mengidentifikasi kemampuan dari abu terbang jenis AluminoSilikat, limbah pertambangan batubara dengan system (CFB). Abu terbang telah digunakan dalam campuran oleh Silitonga E., [14] [17] dalam menstabilisasi limbah pelabuhan dari pelabuhan Cherbourg (Basse Normandie, Perancis). Pada penelitian ini, abu terbang yang khusus diproduksi untuk keperluan pekerjaan stabilisasi. Seperti ygn telah disebutkan diatas, apabila material yang akan digunakan terkontaminasi logam berat, selain dapat membahayakan bagi lingkungan sekitar dan manusia, kadar polutan dalam limbah dapat menghambat reaksi semen dan kapur dalam meningkatkan performa. Penelitian dilakukan oleh Silitonga [8][10] dalam menstabilisasi sedimen sangat terkontaminasi logam berat memperlihatkan bahwa, penambahan Silica Fume dengan dosis tertentu, tidak hanya meningkatkan karakteristik geoteknik dari bahan tersebut akan tetapi juga dapat menurunkan kadar polutan logam berat yang berada dalam sedimen hasil pekerjaan pengerukan tersebut. [11][12]. Berdasarkan hasil penelitian yang menggunakan stabilisasi tanah dengan Silica Fume [9][13][15][16], penurunan yang signifikan terlihat pada percobaan TCLP (Toxicity Leaching Procedure) dimana kadar cadmium dan kadar Zinc. Hal ini disebabkan oleh kemampuan Silica Fume dalam memperangkap elemen-elemen logam berat tetap berada didalam campuran dan tidak menembus dan menyebarkan polisi kelingkungan sekitar. Hal ini disebabkan oleh kemampuan Silica Fume menjadi filler didalam campuran.

\section{Kajian Pustaka}

\subsection{Karakteristik Material Abu Terbang Alumino-Silikat}

Ukuran Partikel

Percobaan identifkasi distribusi diameter partikel pada abu terbang Alumino-Silikat ini digunakan dengan menggunakan alat laser diffractometer Coulter LS200, Alat ini dapat mengidentifikasi ukuran partikel sampai dengan ukuran $<2 \mu \mathrm{m}$. Hasil percobaan diperlihatkan pada gambar 1. Hasil Percobaan pada Gambar 1 menunjukkan bahwa partikel yang membentuk dua jenis abu terbang semuanya memiliki diameter antara 0,04 mikron dan 300 mikrometer. Tampaknya partikel yang paling banyak diwakili memiliki diameter 34 mikron untuk AB/AS-1, dan 18 mikron untuk AB/AS-2. Kurva AB/AS-2 menunjukkan puncak kedua antara $116 \mu \mathrm{m}$ dan $270 \mu \mathrm{m}$ dengan persentase minus $2 \%$, yang berarti bahwa AB/AS-2 mengandung lebih banyak partikel dengan diameter antara $116 \mu \mathrm{m}$ dan $270 \mu \mathrm{m}$ daripada AB/AS-1. Hasil memperlihatkan bahwa AB/AS-1mengandung lebih banyak partikel dengan diameter seperti silts, clays, dan koloid, sedangkan AB/AS-2 di sisi lain, AB/AS-2 mengandung lebih banyak partikel besar $(19,2 \mu \mathrm{m})$ daripada $A B / A S-1$ $(17,5 \mu \mathrm{m})$. , dibandingkan dengan D50 (rata-rata diameter partikel). Ini berarti bahwa AB/AS-1 memerlukan rasio $\mathrm{W} / \mathrm{C}$ yang lebih tinggi, dan AB/AS-2 kurang tahan terhadap serangan sulfat daripada AB/AS-1.

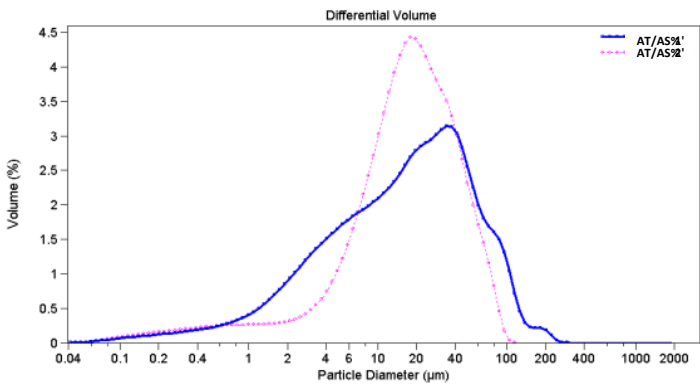

Gambar 1. Distribusi Diameter Partikel Abu Terbang Alumino Silikat

Seperti yang telah diketahui bahwa rasio air dan semen yang lebih tinggi, ini memungkinkan hidrasi medium berpori dan pembentukan kristal besar kalsium hidroksida dan ettringit, senyawa yang bertanggung jawab atas pembengkakan / perluasan mortar. Kecilnya diameter partikel adalah salah satu karakteristik fisik utama fly ash. Jika kita menambahkan bentuknya, mereka memiliki pengaruh besar pada penanganan dan reaksi pozzolanic. Semakin halus butirannya, semakin besar kemampuan kerja campuran, dan semakin banyak reaksi pozzolanic yang akan meningkat. Workability dari pasta sangat penting di lapangan karena menentukan durasi dimana adonan bisa bekerja. Persentase partikel dengan diameter lebih dari $45 \mu \mathrm{m}$ memiliki efek negatif terhadap kekuatan daya tekan pada 28 dan 90 hari. Di sisi lain, persentase partikel yang diameternya kurang dari $10 \mu \mathrm{m}$ memiliki efek positif pada resistansinya. Jadi dengan Tabel 3, kita bisa menentukan persentase partikel sehingga diameter lebih besar dari 45 mikron untuk AB/AS-1 kita dapatkan 18,21\%, tapi untuk AB/AS-2 kita memiliki 19,9\%. Untuk persentase partikel dengan diameter kurang 


\section{Identifikasi Karakteristik Abu Terbang Jenis Alumino-Silikat}

dari $10 \mu \mathrm{m}, \mathrm{AB} / \mathrm{AS}-1$ mengandung 35,49\%, dan AB/AS-2 27,20\%. Artinya AB/AS-1 akan lebih kuat dari Sodeline.

Karakteristik Mineralogy

AB/AS-1 dan AB/AS-2 merupakan abu terbang Alumino-Silikat, yang berasal dari pembakaran Circulating Fluidized Bed (CFB pada suhu rendah $\left(850^{\circ} \mathrm{C}\right)$. Pada table 1 dapat kita perhatikan komposisi abu terbang, Abu terbang ini bersifat silico-aluminous namun dengan tingkat belerang dan kapur yang lebih tinggi daripada abu konvensional

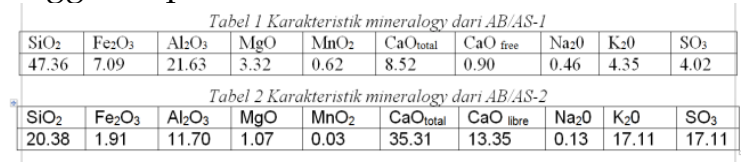

Menurut Tabel 1 dan 3, perbedaan utama komposisi antara dua abu terbang yang terdiri dari kandungan kalsium oksida, silika dan sulfat. AB/AS-2 mengandung lebih banyak kapur (CaO), sedikit silika (SiO2), dan lebih banyak sulfat (SO3) dibanding AB/AS-1. Sebuah studi ukuran partikel menunjukkan bahwa sampel yang diayak $2 \mathrm{~mm}$ dari dua abu memiliki proporsi butir halus dan bola yang sama.

\section{Karakteristik Kapur}

Pada penelitian ini, percobaan direalisasikan dengan menggunakan dua kapur yang berbeda, Kapur 1 (L1) dan kapur 2 (L2). Dalam upaya menentukan tingkat reaktivitas dari kapur tersebut, direalisasikanlah percobaan dengan menggunakan waktu dan suhu. Gambar Tes reaktivitas tertentu memberikan hasil yang tidak umum untuk kapur yang digunakan dalam rekayasa jalan. Kapur ini tercatat L1 dalam penelitian ini, dibandingkan dengan kapur kedua yang diberikan oleh Surchiste, tercatat L2.

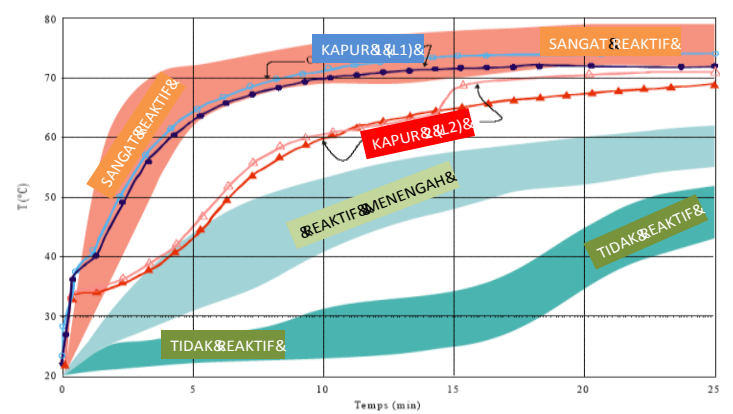

Gambar 2. Hasil percobaan reaktivitas terhadap 2 jenis kapur yang berbeda (L1 dan L2

\section{Karakteristik Semen}

Semen yang digunakan pada percobaan ini merupakan type semen CEM I Portland 42,5 R. Pada table dibawah ini (table 3) diperlihatkan hasil dari Unconfined Compressive Stregth (UCS) dari tiap-tiap obat.

Tabel 3. Kekuatan UCS Dari Semen I Portland 42,5

\begin{tabular}{ccc}
\hline & $\begin{array}{c}\text { Cement I Portland } \\
\text { 42,5R }\end{array}$ \\
\hline $\begin{array}{c}\text { Surface spécifique } \\
\text { Blaine }\left(\mathrm{cm}^{2} / \mathrm{g}\right)\end{array}$ & 4200 & 4210 \\
\hline$\%$ air yg dibutuhkan & 27.2 & 27.0 \\
\hline Waktu yang & 165 & 160 \\
dibutuhkan & & \\
\hline Unconfined & & \\
Compressive & & \\
Strength & & 20 \\
(N/ mm $\left.{ }^{2}\right)$ & 21 & 34 \\
1 day & 34 & 50 \\
2 days & 50 & 60 \\
7 days & 60 & \\
28 days & & \\
\hline
\end{tabular}

\section{Komposisi Campuran}

Pembuatan sampel direalisasikan berdasarkan komposisi yang telah ditentukan. Setiap komposisi direalisasikan untuk mengidentifikasi kehadiran tiap-tiap agen (semen kapur dan abu terbang). Persentase yang berbeda dilakukan untuk mengidentifikasi kehadiran masing agen terhadap performa.

Tabel 4. Tabel Komposisi Campuran

\begin{tabular}{ccccccc}
\hline & 80AT1_15L1 & $80 \mathrm{ATI} \_$15L2 & 80 AB/AS-2_15L1 & 80 AB/AS-2_15L2 75 AB/AS-1_20L1 75 AB/AS-1_15L1 \\
\hline AB/AS-1 & 80 & 80 & - & - & 75 & 75 \\
\hline AB/AS-2 & - & - & 80 & 80 & - & - \\
\hline Kapur 1 (L1) & 15 & & 15 & - & 20 & 15 \\
\hline Kapur 2 (L2) & - & 15 & - & - & - & - \\
\hline Semen & 5 & 5 & 5 & 5 & 5 & 10 \\
\hline
\end{tabular}

\section{Hasil dan Pembahasan}

\subsection{Percobaan Chapelle}

Uji Chapelle menghitung jumlah $\mathrm{CaO}$ bebas yang tersedia untuk reaksi pozzolanic, dan dengan demikian menentukan konsentrasi ion hidroksida dari larutan. Dalam deskripsi asli dari uji Chapelle, solusinya diaduk pada suhu 1000C. Uji Chapelle merupakan suatu percobaan yang berguna untuk menghitung jumlah $\mathrm{CaO}$ bebas yang tersedia untuk reaksi pozzolanic. Reaksi tersebut menciptakan media yang sangat kuat yang membantu mengurangi keasaman bahan. Ini berarti $\mathrm{pH}$ meningkat dari 7 sampai 12 atau lebih.Hal ini sangat penting 


\section{Ernesto Silitonga}

untuk membentuk reaksi pozzolanic, sesuai dengan hubungan berikut:

$$
\begin{aligned}
& \mathrm{Ca}^{++}+2[\mathrm{OH}]^{-}+\mathrm{SiO}_{2} \rightarrow \text { C-S-H } \\
& \quad \text { (Silicate) } \\
& \mathrm{Ca}^{++}+2[\mathrm{OH}]^{-}+\mathrm{Al}_{2} \mathrm{O}_{3} \rightarrow \text { C-A-H }
\end{aligned}
$$

(Aluminate)

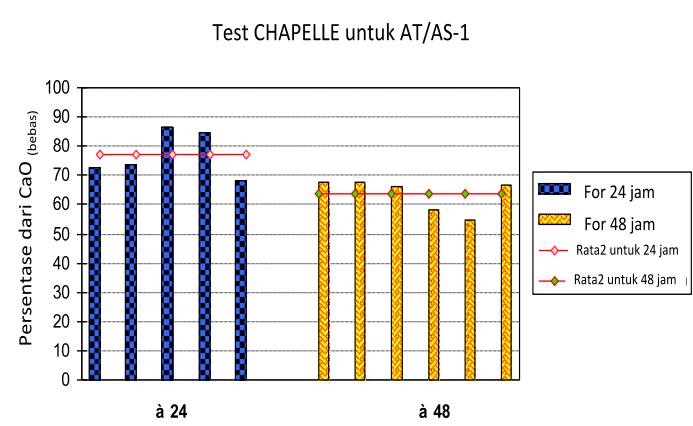

Gambar 3. Hasil Chapelle test terhadap AT/AS-1

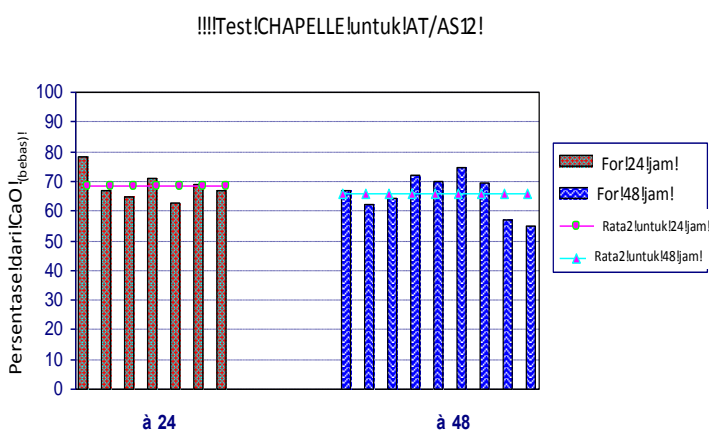

Gambar 4. Hasil Chapelle test terhadap AT/AS-2

Hasil percobaan Chapelle test diperlihatkan pada Gambar 3. Pada Gambar 3, kita dapat melihat bahwa persentase $\mathrm{CaO}$ bebas untuk AT/AS-2 pada 48 jam lebih rendah daripada yang diperoleh pada 24 jam, perbedaan besar di antara keduanya, berarti reaksi pozzolanic untuk AT/AS-2 berlanjut sampai akhir. 24 jam. Memang semakin banyak reaksi berlanjut, dengan $\mathrm{CaO}$ kurang tersedia untuk reaksi pozzolanic. Sebaliknya, pada Gambar 4, persentase $\mathrm{CaO}$ bebas untuk AT/AS-1 pada 24 jam dan 48 jam hampir sama, ini berarti bahwa reaksi AT/AS-1 selesai setelah 24 jam. Jadi kita bisa mengatakan bahwa reaksi pozzolanic berdasarkan $A T / A S-1$ lebih kuat dari pada AT/AS-2.
Tabel 4. Persentase rata-rata $\mathrm{Ca}$ Free dalam campuran

\begin{tabular}{ccccc}
\hline \multirow{2}{*}{$\begin{array}{c}\mathrm{CaO} \\
(\%)\end{array}$} & \multicolumn{2}{c}{$A T / A S-2$} & \multicolumn{2}{c}{ AT/AS-2 } \\
\cline { 2 - 5 } & $\mathbf{2 4}$ jam & $\mathbf{4 8}$ jam & $\mathbf{2 4}$ jam & $\mathbf{4 8}$ jam \\
\hline $\begin{array}{c}\text { Rata-rata } \\
(\%)\end{array}$ & 68,73 & 67,02 & 77,17 & 63,63 \\
\hline $\begin{array}{c}\text { Standar } \\
\text { deviasi } \\
(\%)\end{array}$ & 4,91 & 8,99 & 8,07 & 5,59 \\
\hline
\end{tabular}

Berdasarkan hasil percobaan pada Tabel 4 maka dapat disimpulkan bahwa:

1. penyimpangan standar persentase $\mathrm{CaO}$ ratarata bebas dalam larutan untuk kedua jenis fly ash pada 24 jam dan 48 jam kurang dari $10 \%$, yang berarti bahwa nilai eksperimen dianggap dapat diterima.

2. Persentase rata-rata $\mathrm{CaO}$ untuk AT/AS-1 dan AT/AS-2 bebas di atas 50\%, yang berarti bahwa reaksi tidak terlalu kuat namun cukup untuk memberikan $\mathrm{CaO}$ bebas untuk reaksi pozzolanic.

3. AT/AS-1 memberi lebih banyak persentase $\mathrm{CaO}$ bebas untuk reaksi pozzolanic dari pada AT/AS-2. Pada akhir reaksi, persentase $\mathrm{CaO}$ untuk Sodeline bebas adalah 67,02\% dan 63,63\% untuk AT/AS-2. Hal ini membuktikan bahwa AT/AS-1 mengandung $\mathrm{CaO}$ yang lebih bebas dari pada AT/AS-2

\section{Simpulan}

Tujuan utama dari penelitian ini adalah mengidentifikasi karakteristik abu terbang Alumino-Silikat yang berasal dari Circulating Fluidized Bed (CFB). Langkah pertama adalah mengkarakterisasi perbedaan antara AT/AS-1 dan AT/AS-2 dengan menganalisa distribusi partikel kedua abu terbang ini. Hasil yang diperoleh menunjukkan bahwa AT/AS-2 mengandung partikel yang lebih kasar, lihat nilai D50. Artinya AT/AS-2 kurang tahan terhadap serangan sulfat dibanding AT/AS-1. Selain itu, kita dapat memperkirakan bahwa pasta AT/AS-1 memiliki kemampuan manuver lebih banyak daripada AT/AS-2. Ini berarti AT/AS-1 bisa lebih mudah diimplementasikan daripada AT/AS-2 dan juga AT/AS-1 membutuhkan lebih sedikit air, untuk mendapatkan manuver campuran AT/AS-2 yang sempurna. Dibandingkan dengan persentase partikel yang diameternya lebih besar dari $45 \mu \mathrm{m}$, yang memiliki efek negatif pada resistance pada 24 dan 90 hari, kita dapat melihat bahwa AT/AS-1 akan lebih 


\section{Identifikasi Karakteristik Abu Terbang Jenis Alumino-Silikat}

tahan dari pada AT/AS-2 (antara hari ke 28 sampai ke-90 hari). Kemudian, kami mencoba untuk mengkarakterisasi aktivitas pozzolanic AT/AS-1 dan AT/AS-2, dengan tes Chapelle yang memungkinkan untuk menentukan jumlah $\mathrm{CaO}$ bebas yang tersedia untuk reaksi pozzolanic. Dengan hasil yang didapat, bisa dikatakan bahwa AT/AS-1 memiliki aktivitas yang lebih intens dibanding AT/AS-2. Reaksi AT/AS-1 berakhir setelah 24 jam sedangkan untuk AT/AS-2, akan berlanjut. Selain itu, reaksi AT/AS-1 memberi lebih banyak $\mathrm{CaO}$ untuk reaksi pozzolanic dari pada AT/AS-2. Akhirnya, kami mencoba untuk mengkarakterisasi resistensi sampel. Kita dapat mengatakan bahwa ketahanan sampel sampai hari ke 90, untuk campuran $\mathrm{m} 6$ (75\% dari AT/AS-1 dan 15\% dari kapur 1) adalah yang tertinggi. Kami merasa penambahan semen itu berpengaruh. Di sisi lain, untuk campuran m1 dan $\mathrm{m} 2$, (80\% Sodeline dengan $15 \%$ kapur dan kapur 2 masing-masing), kurva resistansi turun tajam setelah 28 hari. Alasannya mungkin karena kesalahan dalam nilai gaya yang diterapkan pada sampel.

\section{Daftar Pustaka}

Silitonga E., Proses stabilisasi limbah pelabuhan terkontaminasi logam berat dengan menggunakan agen pengikat hdirolik, Proceeding Seminar Nasional Gempa Sumatera Utara: Resiko dan Antisipasinya, p 140-147 (2017)

Silitonga E., Proses stabilisasi sedimen pelabuhan terkontaminasi logam berat dalam penggunaanya pada pekerjaan pembangunan jalan raya.dengan menggunakan agen pengikat hdirok, Proceeding Seminar Nasional Energi dan Teknologi (SINERGI) 9 Mei 2017, p 537-544 (2017)

Silitonga, E., Stabilization / solidification of polluted marine dredged sediment of port en Bessin France, using hydraulic binders and silica fume, IOP Conference series; Material Science and Engineering, Vol 237, 6p, (2017)

Silitonga, E., Stabilisasi dan identifikasi sedimen hasil pekerjaan pengerukan, Educational Building, vol. 2 no. 2, (2016)
Silitonga E., Pengaruh kontaminasi logam berat pada sedimen hasil pekerjaan pengerukan sebagai material baru dalam pekerjaan pembangunn jalan.Proceeding Seminar Nasional Teknik Sipil XII, pp 468-477, (2016)

Silitonga E., Pengaruh penambahan Silica Fume pada karakteristik geoteknik dan kimia dari limbah pelabuhan dalam penggunaannya pada pekerjaan pembangunan jalan, Educational Building, vol. 3, no. 1 (2017)

Silitonga E., Levacher D., Mezazigh S, Utilization of fly ash for stabilization of marine dredged sediments, European Journal of Environmental and Civil Engineering, vol. 14, issue 2., pp 253-265 (2010).

Silitonga E., Valorisation des sédiments Marins contaminés par solidification/ stabilisation à base de liants hydrauliques et de fumée de silice. Thesis doctorat Université de Caen, France, 160p, (2010)

Silitonga E., Reutilisasi sedimen hasil pekerjaan pengerukan sebagai material baru dalam pekerjaan pembangunan jalan, Educational Building, vol. 2, no. 1 (2016)

Silitonga E., Siregar S., Sebayang N., Taufik R., Reutilisasi sedimen hasil pekerjaan pengerukan sebagai material baru dalam pekerjaan pembangunan jalan, Proceeding seminar nasional HAKI; Indonesia siaga gempa, pp 125-132, (2014)

Silitonga E., Sebayang N., Siregar S., Taufik R., Reutilisasi sedimen hasil pekerjaan pengerukan sebagai material baru dalam pekerjaan pembangunan jalan, Proceeding Seminar Nasional dan Pameran Konstruksi Himpunan Ahli Konstruksi Indonesia Komda Sumut 2015, 5-6 Jun 2015, Medan, pp 1216-23, (2015)

Silitonga E., Mezazigh S., Levacher D., Etude de la durabilité de sédiments marins traités avec différents types de fumée de silice, proceeding of XIèmes Journées Nationales Génie Côtier Génie Civil, Les Sables d'Olonne, 2225 juin 2010, p 895-907 (2010)

Silitonga E., Stabilisasi limbah terkontaminasi logam berat pada pekerjaan pengerukan pelabuhan dengan menggunakan Silica Fume, Proceeding Seminar Nasional 
Seminar Nasional Sains, Rekayasa \& Teknologi (SNSRT) 2017, 17-18 May 2017, pp 1216-23, (2017)

Silitonga E., Mezazigh S, Levacher D., Characterization of mechanical properties of dredged marine sediment stabilized by fly ash, Conférence Méditerranéenne Côtière et Maritime, edition 1, Hamamet, Tunisie, pp 155-158 (2008).

Mezazigh S., Silitonga E., Lei X., Bai X., Etude de la durabilité des sédiments de dragage du port d'Honfleur traités au ciment et additifs, proceeding of XIIèmes Journées Nationales Génie Côtier - Génie Civil, Cherbourg, 12-14 juin 2012, pp 1075-1084 (2012)

Silitonga E., Levacher D., Mezazigh S., Effects of theuse of fly ash as a binder on the mechanical behavior of treated dredged sediments, Environmental Technology vol 30. (2009) 